\title{
Tom e Jack. As vidas entrelaçadas de Thomas Hart Benton e Jackson Pollock
}

\begin{abstract}
ADAMS, Henry. Tom and Jack: the intertwined lives of Thomas Hart Benton and Jackson Pollock. New York: Bloomsbury Press, 2009, 408 p.
\end{abstract}

Roberto Carvalho de Magalhães

Na história da arte norte-americana, não há dois artistas que, a uma primeira impressão, possam parecer mais antitéticos do que Thomas Hart Benton e Jackson Pollock. O primeiro, um grande protagonista, especialmente nos anos 20 e 30 do século passado, da assim chamada pintura da American Scene, categoria na qual, ainda hoje, são enquadrados os pintores figurativos daquele período que utilizavam temas americanos - a vida rural, o Middle West, as cidades e os seus respectivos trabalhadores e grupos sociais - como se, por antonomásia, a sua pintura se limitasse somente aos temas narrativos e à tarefa menos nobre de ilustrar. O segundo é o inventor da action painting e do dripping, e a sua pintura, desde o seu primeiro grande defensor - o crítico Clement Greenberg — é, geralmente, considerada abstrata, sem nenhum vínculo figurativo; e, portanto, a serviço da tarefa mais nobre de expressar sem representar.

Entretanto, Benton e Pollock não só foram mestre e discípulo, mas também uma espécie de substitutos de pai e filho um para o outro. Como afirma Henry Adams, neste esplêndido tratado de história e crítica de arte:

os escritores sobre Pollock negligenciaram um ingrediente fundamental — a influência de Thomas Hart Benton, mestre e figura paterna, sobre Pollock [...] este recebera a sua única educação artística formal de Benton, aprendera a pintar como o mestre e, durante seis anos, vivera praticamente como um membro da família Benton. De fato, Benton tornara-se uma espécie de pai substitutivo para Jackson Pollock — um substituto para o pai fraco e ausente que a natureza lhe tinha dado — assim como, para Benton, Pollock tinha-se tornado um

\footnotetext{
* Università Internazionale dell'Arte di Firenze, Itália. gamacor12@hotmail.com
} 
filho substitutivo [...] É curioso que, não obstante a ligação entre as duas figuras fosse tão forte, os estudiosos de Pollock tenham ignorado esse dado sistematicamente. Com certeza, uma das razôes para isso encontra-se no fato de que Benton é, geralmente, estigmatizado como um artista "conservador" — o que, aliás, está longe da verdade. Enquanto Pollock é visto como um exemplo de tudo o que há de mais estimulante na arte moderna, Benton é identificado com o que há de mais errado e reacionário. (p. 10-11).

No seu livro, Henry Adams, professor de História da Arte Americana na Case Western Reserve University de Cleveland, não só retraça minuciosamente o encontro entre os dois homens, a relação entre mestre e discípulo no Art Students League de Nova York e a sua transformação em uma ligação mais profunda, íntima, mas também reconstrói e analisa a atividade artística dos dois a cada passo — e o contexto histórico-artístico em que se desenvolve —, revelando, na obra de Pollock, derivaçooes do ensino de Benton insuspeitáveis a um olhar superficial. Aliás, ligaçôes ocultadas por décadas de uma crítica de arte que tendia e ainda tende à comodidade das simplificações e das divisōes em categorias. Aos defensores e prosélitos da arte abstrata, era conveniente um Thomas Hart Benton figurativo, regionalista e conservador, e um Pollock que tinha rompido relaçôes com o mestre, pessoais ou artísticas.

Ainda no final dos anos 1980, pouco tempo depois de uma retrospectiva dedicada a Thomas Hart Benton na Fine Arts Gallery, de Kansas City, com curadoria do próprio Henry Adams, o ex-crítico de arte do New York Times, Hilton Kramer, chegava a dizer em um documentário:

Vinte e cinco anos atrás, ninguém imaginaria que haveria um revival de Thomas Hart Benton. A ideia de arte subjacente à sua obra, nos seus escritos, na sua carreira parecia definitivamente morta... A sua obra, para mim, é uma espécie de cadáver que foi exumado... Para mim, não existe como objeto estético ${ }^{1}$.

Porém, como muitos de nós suspeitávamos e como o livro de Adams demonstra amplamente, as visōes do "painter of America", como era chamado Thomas Hart Benton, não só vão muito além da ilustração ou da caricatura, mas são, também, uma explosão de força criativa e encerram em si uma reflexão profunda sobre a atividade artística e sobre o estilo. O livro revela como Benton era um mestre excelente, que atraía estudantes como o mel atrai as moscas. É assim que Pollock

\footnotetext{
I. In: Thomas Hart Benton, 1988, filme de Ken Burns e disponível em DVD da PBS Home Video.
} 
acaba entrando no círculo de Benton e absorve o métier desse admirador das técnicas de composição de Tintoretto, dos estudos sobre o volume da figura humana de Luca Cambiaso e das pesquisas sobre o "côncavo e o convexo". De fato, as figuras de Thomas Hart Benton têm o ímpeto das figuras de Tintoretto e a energia das de Michelangelo e inserem-se num espaço extremamente dinâmico, ondulante e mutável, um resultado de uma refinada manipulação da perspectiva. Isto, junto com as medidas amplas dos seus murais e um uso da cor que ultrapassa o registro real, torna as suas visões da América extremamente potentes e envolventes. Como observa o crítico Arthur Danto no documentário de Ken Burns citado acima,

ele estava buscando dar uma finalidade humana à arte, colocar-se ao serviço de um desígnio humano, tornar os americanos de algum modo vivos numa dimensão profunda da sua realidade. Acho que é uma grande finalidade para se dar à arte. Ele procurava ser... Tintoretto em Kansas! Adotava estratégias dos séculos XVI e XVII num país do século vinte e utilizava o dinamismo da 'grande arte' para comunicar uma mensagem simples a pessoas simples. Creio que isso é verdadeiramente grande.

Pode-se dizer que Thomas Hart Benton tinha-se encarregado da enorme tarefa não só de contar a América aos americanos, mas também de fornecer ao país um conjunto de obras originais que tivessem uma dimensão de referência artísticocultural, assim como os grandes ciclos de pintura do Renascimento e do período barroco o eram (e são) para os países europeus. Benton queria criar uma "história da arte" que ainda não existia na América. Esse é um fenômeno consideravelmente generalizado no século 20 nos países do Novo Mundo, exemplificado em outros países pela pintura de Orozco, Diego Rivera e Cândido Portinari ou, em âmbito musical, pelos conjuntos imensos e variegados de obras de Heitor Villa-Lobos e Aaron Copland.

Pollock tinha absorvido de Benton exatamente essa aspiração à grandeza, o dinamismo das composiçóes derivado do estudo de Tintoretto e as pesquisas sobre o côncavo e o convexo. Como nota Henry Adams, o método de Benton é evidente no caderno de desenhos de Pollock pertencente ao Metropolitan Museum of Art, "repleto de estudos de composição baseados em Signorelli, Michelangelo, Tintoretto, El Greco e Rubens, os artistas que Benton recomendava estudar com atenção" (p. 54).

Os primeiros quadros de Pollock também não deixam dúvidas sobre a sua ligação com os ritmos ondulantes ou circulares das composições de Benton. Tais ritmos tornar-se-ão, mais tarde, como demonstra Adams, um dos alicerces da obra da maturidade de Pollock e fornecerão a estrutura sobre a qual se estratificarão fragmentos figurativos e dripping. Essas sobreposiçōes "infundem a ideia de dois 
mundos diferentes, o do espaço sideral ou cosmos e o do misterioso mundo do quase infinitamente pequeno, o mundo das forças atômicas". (p. 324).

Lançando mão de todos os fatos e de todos os artistas que pudessem esclarecer a relação entre as obras de Pollock e de Benton, Henry Adams dá um significado novo a muitos documentos e a textos conhecidos, revela outros menos frequentados e ministra uma verdadeira aula sobre a arte americana do século 20, das vanguardas históricas ao assim chamado expressionismo abstrato. E, acima de tudo, com suas reconstruçōes aprofundadas, seja da atividade artística de Benton e Pollock, seja de outros artistas como Stanton Macdonald-Wright e Morgan Russel, para citar somente dois, demole muitos lugares-comuns que pairam sobre a história da arte americana. Em suma, das suas pesquisas minuciosas, emergem duas figuras e duas obras infinitamente mais ricas e multifacetadas: Benton aparece mais "abstrato" - ou seja, intérprete de uma cultura artística e criador de um estilo que vão muito além da simples "representação" da cena americana — e Pollock revela-se surpreendentemente figurativo, ainda que não no tradicional sentido narrativo ou representativo do termo.

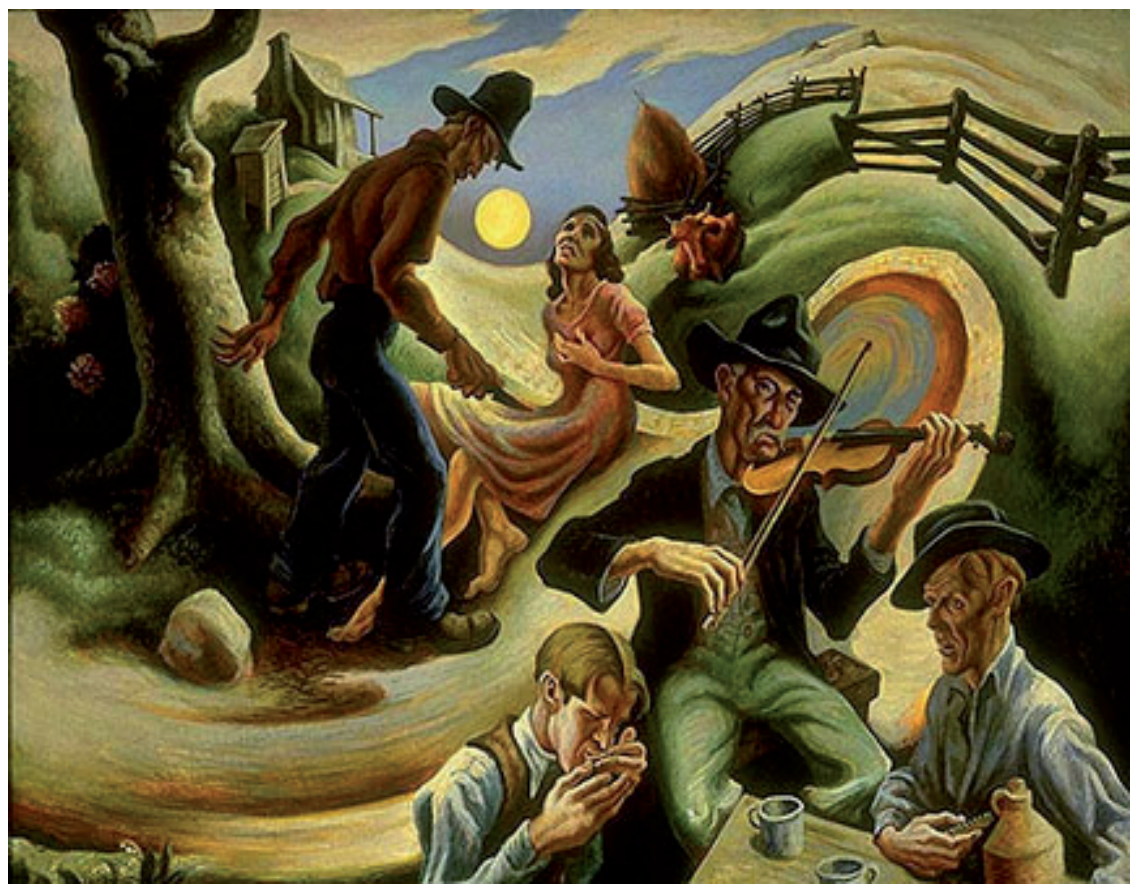

Thomas Hart Benton, A balada do amante ciumento de Lone Green Valley, 1934, Kansas University Spencer Museum of Art.

O jovem Jackson Pollock aparece tocando gaita na parte baixa da composição. 


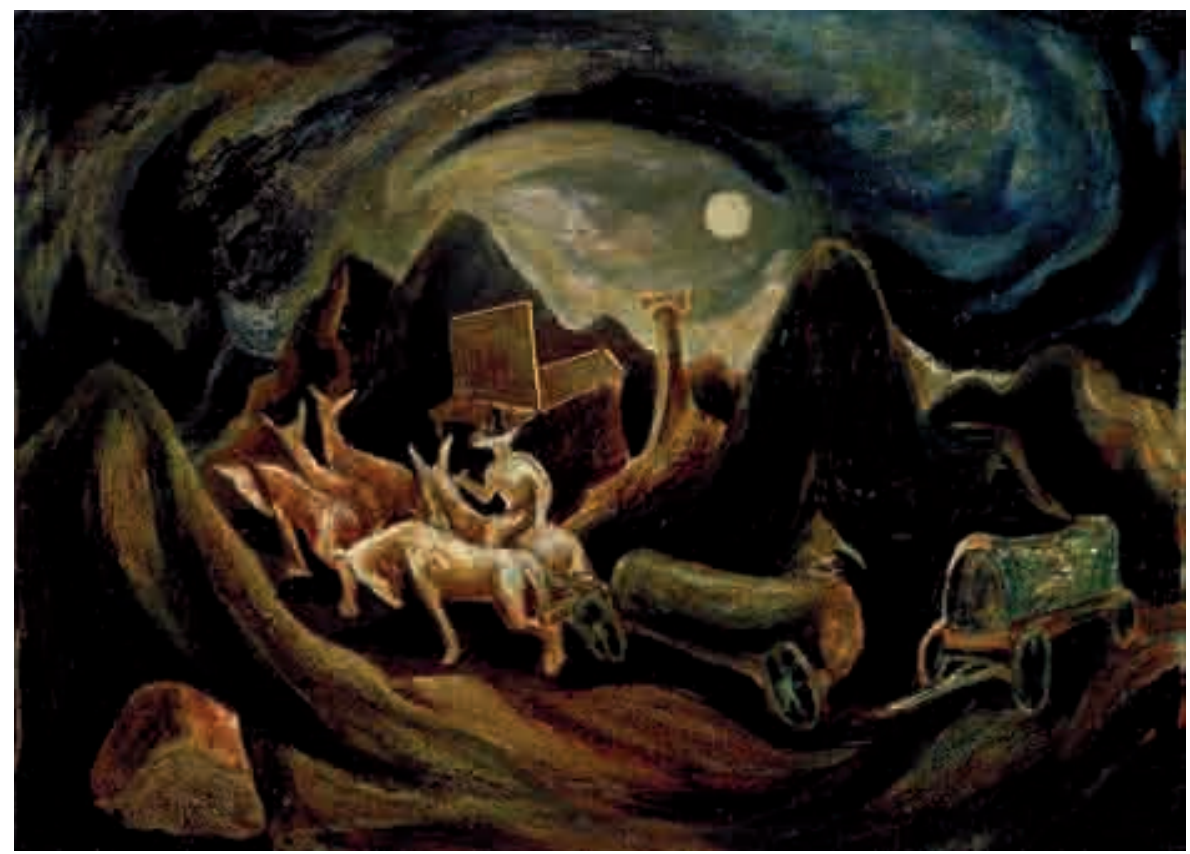

Jackson Pollock, Indo para o Oeste, 1934-35, Smithsonian American Art Museum, Washington D.C.

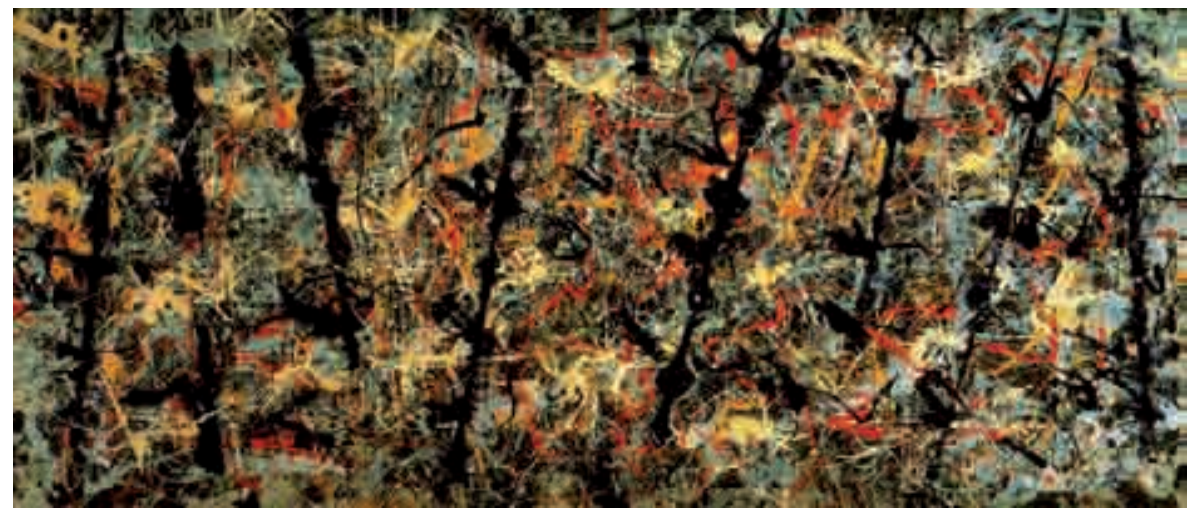

Jackson Pollock, Postes azuis, 1952, National Gallery of Australia, Canberra. 